\title{
GCU
}

Glasgow Caledonian

University

University for the Common Good

\section{Training health visitors in cognitive behavioural or person-centred approaches is cost- effective and can improve outcomes for women at risk of postnatal depression}

Parkinson, Ben; MacDonald, Emma

Published in:

Evidence Based Nursing

DOI:

10.1136/ebnurs-2018-103010

Publication date:

2018

Document Version

Author accepted manuscript

Link to publication in ResearchOnline

Citation for published version (Harvard):

Parkinson, B \& MacDonald, E 2018, 'Training health visitors in cognitive behavioural or person-centred approaches is cost-effective and can improve outcomes for women at risk of postnatal depression', Evidence Based Nursing, vol. 22, no. 1, pp. 26-27. https://doi.org/10.1136/ebnurs-2018-103010

\section{General rights}

Copyright and moral rights for the publications made accessible in the public portal are retained by the authors and/or other copyright owners and it is a condition of accessing publications that users recognise and abide by the legal requirements associated with these rights.

Take down policy

If you believe that this document breaches copyright please view our takedown policy at https://edshare.gcu.ac.uk/id/eprint/5179 for details of how to contact us. 


\section{Category:}

\section{Study type:}

Citation: Henderson, Catherine, et al. Cost-Effectiveness of PoNDER Health Visitor Training for Mothers at Lower Risk of Depression: Findings on Prevention of Postnatal Depression from a Cluster-Randomised Controlled Trial. Psychological Medicine 2018; 1-11, doi:10.1017/S0033291718001940.

Declarative title: Training health visitors in cognitive behavioural or person centred approaches is cost-effective and can improve outcomes for women at risk of postnatal depression.

\section{Commentary}

\section{Implications for practice and research}

- $\quad$ Health visitors should be trained and supported to deliver cognitive behavioural or person centred approaches.

- $\quad$ Research should be undertaken to determine whether PoNDER remains clinically effective and cost-effective when delivered by other health professionals.

- $\quad$ Future research should explore the longer-term cost-effectiveness and social impact of using PoNDER with women experiencing postnatal depression.

\section{Context}

Postnatal depression (PND) is common and can have a negative impact on both maternal and infant health. ${ }^{1}$ PND affects maternal-infant interaction and can lead to long-term adverse outcomes for children. ${ }^{1}$ Health Visitors (HVs) in the United Kingdom (UK) offer a universal service to all new mothers. The original POstNatal Depression Economic evaluation and Randonmised (PoNDER) trial examined the effectiveness of training HVs to assess mood, identify depression, and deliver either cognitive behavioural (CBA) or person centred approaches (PCA). ${ }^{2}$ Findings from the trial demonstrated PoNDER was effective when working with women who scored $>12^{2}$ or $<12^{3}$ on the Edinburgh Postnatal Depression Scale (EPDS). ${ }^{4}$

\section{Methods}

This study ${ }^{5}$ completed an economic evaluation to determine the costeffectiveness of HVs using PoNDER with women at risk of PND. It examined data collected as part of the original PoNDER trial completed between 2003$2006^{2-3}$. The analysis focused on women who scored $<12$ on the EPDS ${ }^{4}$ and were thought to be low risk for PND. The study considered the implementation costs for PoNDER and whether it achieved reductions in HV contact and/or use of health services. Cost-effectiveness calculations used estimated prices from 2003/2004 and were completed for 1459 women (1042 PoNDER and 417 controls). Quality-adjusted life-years (QALY) and risk of depression were calculated to determine the impact PoNDER had on mothers between 6weeks and 6-months following birth. ${ }^{5}$

\section{Findings}


The combined intervention groups (CBA \& PCA) had significantly $(p=<0.001)$ fewer visits with the HV between 6 -weeks and 6-months. ${ }^{5}$ Those women in the CBA group spent 62 minutes less $(p=0.049)$ time with their HV. Women in the PCA group spent roughly the same amount of time with the HV as the control group $(p=0.156)$. Overall, costs for women receiving PoNDER were significantly ( $p=0.028)$ lower ( $£ 72$ per person) than those receiving 'care as usual'. ${ }^{5}$ Statistically significant $(p=0.046)$ changes in QALY were reported in the PoNDER groups at 6-months. Risk of depression did not change significantly for those involved in the cost-effectiveness analysis who were receiving PoNDER. ${ }^{5}$

\section{Commentary}

Clinically effective and financially viable psychological interventions have an important role to play in the care of women with PND and can positively impact maternal-infant health. ${ }^{6}$ PoNDER helps prevent depression in women who score $<12^{3}$ on the EPDS ${ }^{4}$ and is cost-effective. Both the CBA and PCA components of PoNDER appear to be equally cost-effective and pay for themselves within 6-months. ${ }^{5}$ Economic evaluations of interventions for PND often focus on maternal health outcomes and calculate cost-effectiveness over a short period of time. ${ }^{6}$ Research indicates PND can impact on other people within the family home and can contribute to marital problems. ${ }^{6}$ Children are particularly vulnerable when they are exposed to persistent maternal PND and can experience adverse childhood outcomes. ${ }^{1}$ This study ${ }^{5}$ calculated the cost-effectiveness of PoNDER at 6-months postnatal and considered maternal risk of depression and QALYs. The economic evaluation was undertaken within the UK using figures from 2003/2004, therefore, the cost-effectiveness will likely change when PoNDER is delivered in different health care systems and/or when using current costs. Future economic evaluations of psychological interventions for PND should consider a wider range of psychosocial outcomes and longer-term outcomes for mother and child. ${ }^{6}$ The findings from this economic evaluation suggest PoNDER should be adopted universally as a preventative intervention for women at low risk of PND. This strategy could reduce health expenditure and improve outcomes for new mothers.

\section{References}

1. Netsi, E. et al. Association of persistent and severe postnatal depression with child outcomes. JAMA psychiatry75.3 (2018): 247-253.

doi:10.1001/jamapsychiatry.2017.4363

2. Morrell, $\mathrm{C}$ Jane, et al. Clinical Effectiveness of Health Visitor Training in Psychologically Informed Approaches for Depression in Postnatal Women: Pragmatic Cluster Randomised Trial in Primary Care. BMJ 2009; 338: 276-80. doi:10.1136/bmj.a3045.

3. Brugha, T S, et al. Universal Prevention of Depression in Women Postnatally: Cluster Randomized Trial Evidence in Primary Care. Psychological Medicine 2001;41: 739-48. doi:10.1017/S0033291710001467. 
4. Cox, J. et al. Perinatal Mental Health: The Edinburgh Postnatal Depression Scale (EPDS) Manual (2nd edn). RCPsych Publications, 2014.

5. Henderson, Catherine, et al. Cost-Effectiveness of PoNDER Health Visitor Training for Mothers at Lower Risk of Depression: Findings on Prevention of Postnatal Depression from a Cluster-Randomised Controlled Trial. Psychological Medicine 2018; 1-11, doi:10.1017/S0033291718001940.

6. Gurung, B. et al. Identifying and Assessing the Benefits of Interventions for Postnatal Depression: a Systematic Review of Economic Evaluations. BMC Pregnancy and Childbirth 2018;18: 1-18. doi:10.1186/s12884-0181738-9.

\section{Commentator details}

Name: Mr. Ben Parkinson

Affiliation: Glasgow Caledonian University

Correspondence address: Glasgow Caledonian University, Cowcaddens Road, Glasgow, G4 OBA, United Kingdom.

Email: ben.parkinson@gcu.ac.uk

Name: Mrs. Emma MacDonald

Affiliation: Glasgow Caledonian University

Correspondence address: Glasgow Caledonian University, Cowcaddens Road, Glasgow, G4 OBA, United Kingdom.

\section{Competing interests}

None 